\title{
'Masked' petrous apicitis presenting with lateral rectus palsy
}

\author{
Stuti Chowdhary (ㄱ) , Arun Alexander (1) , Saranya Thangavel (ㄱ) , \\ Lokesh Kumar Penubarthi
}

ENT, Jawaharlal Institute of Postgraduate Medical Education and Research, Puducherry, Puducherry, India Correspondence to
Dr Stuti Chowdhary;
stuti.9894@gmail.com

Accepted 4 July 2021

\section{DESCRIPTION}

A 31-year-old man was referred to the ear, nose and throat outpatient clinic with a right-sided hemicranial headache and diplopia of 2-week duration. He had no significant otologic complaints except for some mild fullness in the right ear. There was no prior history of any antibiotic therapy or ear surgery. On examination, the patient had a rightsided lateral rectus palsy (figure 1 ). The tympanic membrane appeared normal bilaterally. There were no signs of any other cranial nerve palsies or signs of raised intracranial pressure.

CT scan of the temporal bone showed a wellpneumatised petrous apex with a soft tissue lesion causing partial destruction of the petrous air cells (figure 2). A T2-weighted MRI of the brain depicted air-fluid levels within the mastoid air cell system and erosions of the body of the sphenoid and the clivus. Meningeal thickening in the Meckel's cave was seen. The facial nerve appeared intact (figure 3). Pure tone audiometry revealed a moderate conductive hearing loss of $45 \mathrm{~dB}$ in the right ear, while a tympanogram revealed reduced compliance. The patient was started on a course of intravenous broad-spectrum antibiotics (crystalline penicillin and ceftriaxone), but a decision was made to operate after a week as the patient had no improvement of symptoms. Preservation of hearing was kept as a priority during surgery, as preoperative hearing status was good enough to warrant labyrinth-preserving approaches.

The patient underwent a canal wall down mastoidectomy and systematically, various cell tracts were explored. The patient had an extensively pneumatised mastoid and exploration of each tract proved time consuming. Finally, surgical drainage of the petrous apex was done via an infralabyrinthine

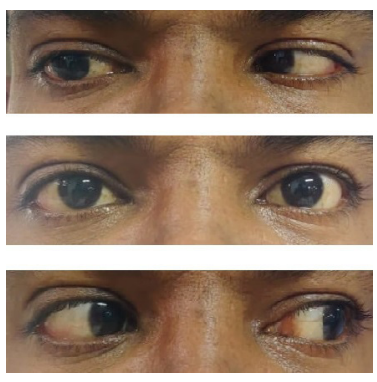

Figure 1 Clinical photograph of the patient obtained preoperatively depicting right lateral rectus palsy (top panel), primary gaze (middle panel) and normal left lateral gaze (bottom panel).

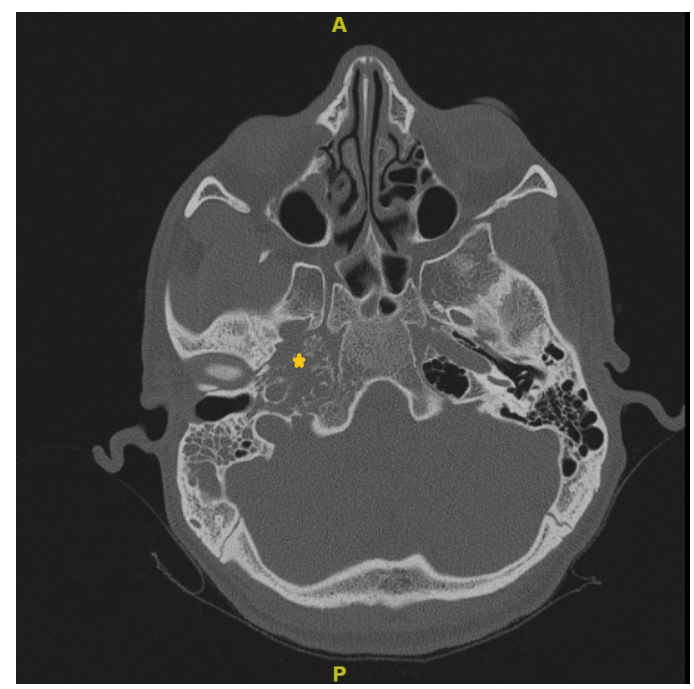

Figure 2 Preoperative CT scan image (high-resolution CT scan, non-contrast, axial section) showing eroded right-sided petrous air cells due to a homogenous soft tissue lesion (yellow asterisk).

approach where a cell tract was identified below the basal turn of the cochlea. The cell tract was widened until the internal carotid artery anteriorly, jugular bulb posteriorly and the basal turn of the cochlea superiorly. The major surgical landmarks were delineated (figure 4). The tract was made of multiple air cells with soft intervening septae and granulation tissue. The tract led to a blind cul-de-sac that was filled with granulation tissue. The granulation tissue was gently removed with a curette. As the opening of the tract appeared wide, a decision was made not to use a silastic stent but to leave the tract open and to cover the mastoid cavity with temporalis fascia graft, which was harvested

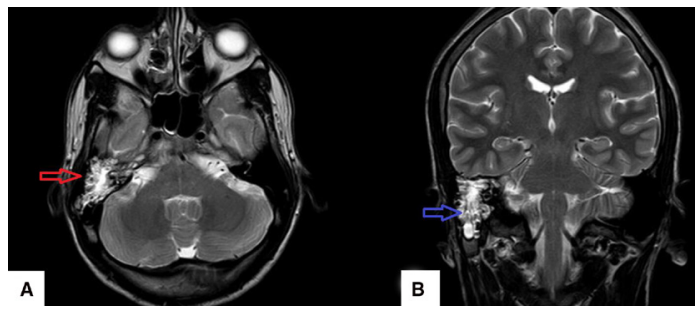

Figure 3 Preoperative MRI (T2 weighted, axial section, the red arrow in (A) on the left, and T2 weighted, coronal section, the blue arrow in (B) on the right) showing fluid intensities within the mastoid air cell system on the right extending to the petrous apex. 


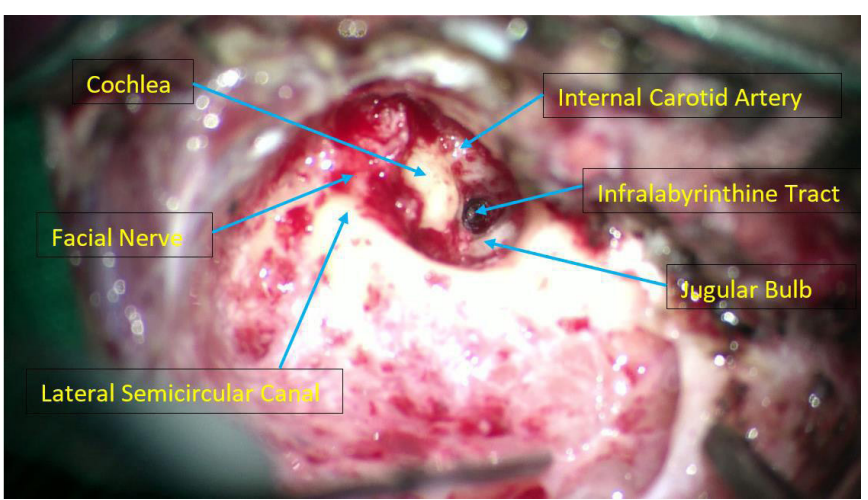

Figure 4 Intraoperative photograph obtained during the exposure of the cell tracts. The various landmarks are depicted.

from the same side. The wound was closed in layers and the patient continued to receive postoperative broad-spectrum antibiotics (crystalline penicillin and ceftriaxone). The postoperative course in the hospital was uneventful. The diplopia and headache resolved within days of the surgical drainage. The postoperative scans showed the petrous apex in continuity with the mastoid cavity (figure 5).

The petrous apex is pyramidal shaped and is located in a relatively inaccessible area of the temporal bone that houses the inner ear's critical structures. Overall, $30 \%$ of normal temporal bones have a well-pneumatised petrous apex, which is predisposed to a contiguous spread of infection from the middle ear. ${ }^{1}$ The spread of the inflammation via various pneumatised cell tracts results in the inflammation and subsequent manifestations in the form of the eponymous Gradenigo's triad. First, the entrapment of the abducens nerve under the petrosphenoid ligament of Gruber as it runs within the Dorello's canal manifests as lateral rectus palsy. Second, extradural inflammation involving the adjoining trigeminal nerve in the Meckel's cave causes deep retro-orbital pain. A discharging ear completes the triad. The complete triad is rare in today's clinical practice due to the early institution of empirical antibiotics. ${ }^{2}$ A constellation of other signs such as fever, otalgia and multiple cranial nerve palsies may be seen instead.

In cases with a lack of clinically significant ear symptoms, the finding of lateral rectus palsy initially points towards the possibility

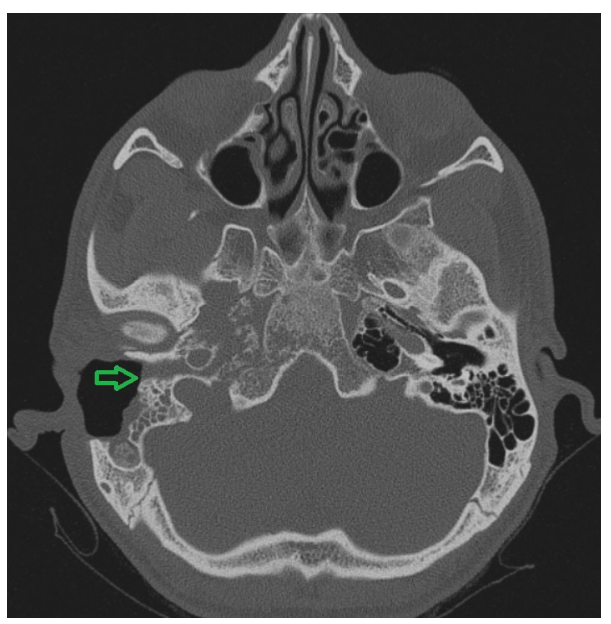

Figure 5 Postoperative CT scan image (high-resolution CT scan, noncontrast, axial section) showing the mastoidectomy cavity directly in continuity with the petrous apex, with minimal intervening soft tissue (green arrow). of a neurological disorder, such as increased intracranial pressure causing the false localising sign. Imaging must be undertaken to identify the pathology and to rule out the presence of other latent complications. Both CT and MRI have contributory roles in the diagnosis by identifying bony erosions and nerve involvement, respectively. ${ }^{3}$ Petrous apicitis as a complication of acute otitis media in children is well documented in the literature. However, petrous apicitis is rarely seen in adults due to empirical antibiotics in patients with ear discharge and headaches.

The treatment of petrous apicitis in a vast number of cases is purely medical using broad-spectrum antibiotics. Surgery is indicated when there is a failure of prolonged antibiotic therapy, osteomyelitis requiring sequestrectomy and complications such as otogenic abscesses. A range of operative procedures has been described, such as insertion of ventilation tubes to radical temporal bone resection in cases of extensive cholesteatomas causing petrous apicitis. ${ }^{4}$ A canal wall down mastoidectomy was done in the present case, and various air cell tracts opened systematically till the infralabyrinthine cell tract was found, which led to the petrous apex. This approach allowed for the conservation of hearing and vestibular functions in this patient.

Clinical features were atypical in this case due to a lack of significant ear complaints. Tubercular mastoiditis and occult meningitis are often overlooked but are potential pathologies that may coexist with petrositis in adults. However, in the absence of overt ear findings with conductive hearing loss and diplopia, the diagnosis of petrous apicitis should be kept in mind. It is prudent to take a postoperative CT scan of the temporal bone to rule out persistent disease or incomplete removal..$^{5}$ The best practice involves the medical management of the disease and surgery is reserved for those patients who do not improve. The timing of the surgery is crucial to avoid permanent nerve palsies, labyrinthitis, intracranial abscesses and death.

Contributors SC: Acquisition of preliminary data, obtaining consent, drafting the initial version of the manuscript and accountability for the integrity of the content. AA: Approval of the final version of the manuscript, contributing intraoperative photographs and critical review of the manuscript. ST: Revising the manuscript for factual and technical accuracy. LKP: Directly involved in patient care, provided crucial insight into the management and revised manuscript for technical content.

Funding The authors have not declared a specific grant for this research from any funding agency in the public, commercial or not-for-profit sectors.

Competing interests None declared.

Patient consent for publication Obtained.

Provenance and peer review Not commissioned; externally peer reviewed.

ORCID iDs

Stuti Chowdhary http://orcid.org/0000-0003-2154-6400

\section{Patient's perspective}

I am delighted that the double vision and severe headache improved within days of surgery.

\section{Learning points}

In isolated lateral rectus palsy, otogenic foci of infection should be ruled out even if the patient does not have overt otologic symptoms.

- Systematic exploration of the various cell tracts in the mastoid must be done and then widened to drain the petrous apex collection in cases of petrous apicitis. 
Arun Alexander http://orcid.org/0000-0003-1026-4678

Saranya Thangavel http://orcid.org/0000-0001-6954-1364

Lokesh Kumar Penubarthi http://orcid.org/0000-0003-1007-7776

\section{REFERENCES}

1 Demir B, Abuzaid G, Ergenc Z, et al. Delayed diagnosed Gradenigo's syndrome associated with acute otitis media. SAGE Open Med Case Rep 2020:8:2050313×20966119.
2 Rossi N, Swonke ML, Reichert L, et al. Gradenigo's syndrome in a four-year-old patient: a rare diagnosis in the modern antibiotic era. J Laryngol Otol 2019;133:535-7.

3 Brambilla A, Pasti M, Parri N. Sudden diplopia at a pediatric emergency department: a case of Gradenigo syndrome in a child. Pediatr Emerg Care 2019;35:e236-7.

4 Isaac H, Liu A, Shibata SB, et al. Transmastoid and Transtemporal drainage of petrous Apicitis with otitis media. Ann Otol Rhinol Laryngol 2021;130:314-8.

5 Gadre AK, Chole RA. The changing face of petrous apicitis-a 40-year experience. Laryngoscope 2018;128:195-201.

Copyright 2021 BMJ Publishing Group. All rights reserved. For permission to reuse any of this content visit https://www.bmj.com/company/products-services/rights-and-licensing/permissions/

BMJ Case Report Fellows may re-use this article for personal use and teaching without any further permission.

Become a Fellow of BMJ Case Reports today and you can:

- Submit as many cases as you like

- Enjoy fast sympathetic peer review and rapid publication of accepted articles

- Access all the published articles

Re-use any of the published material for personal use and teaching without further permission

\section{Customer Service}

If you have any further queries about your subscription, please contact our customer services team on +44 (0) 2071111105 or via email at support@bmj.com.

Visit casereports.bmj.com for more articles like this and to become a Fellow 